\title{
Lípidos sanguíneos en cerdos alimentados con pijiguao (Bactris gasipaes Kunth) y lisina sintética
}

\section{Blood lipids of pigs fed peach palm (Bactris gasipaes Kunth) and synthetic lysine}

\author{
Janeth Colina R, 1,2* Ph.D, Adriana Méndez O, 1,2,3 M.Sc, Humberto Araque M, 1,4,5 M.Sc, \\ Emma Rueda de A, 1,2,6 M.Sc, Milagro León T, 1,2,3 M.Sc, Mario Rossini V, 1,2 M.Sc.
}

\begin{abstract}
${ }^{1}$ Universidad Central de Venezuela. ${ }^{2}$ Facultad de Ciencias Veterinarias. ${ }^{3}$ Centro de Bioquímica Nutricional. ${ }^{4} \mathrm{Facultad}$ de Agronomía. ${ }^{5}$ Instituto de Producción Animal. ${ }^{6}$ Laboratorio de Enzimología y Toxicología Veterinaria. 'Laboratorio de Patología Clínica. Maracay Estado Aragua. 2101. Venezuela. *Correspondencia: janeth.colina@ucv.ve
\end{abstract}

Recibido: Octubre de 2010; Aceptado: Junio de 2011.

\section{RESUMEN}

Objetivo. Evaluar el efecto de la harina de pijiguao y lisina sintética sobre los lípidos sanguíneos de cerdos en crecimiento y engorde. Materiales y métodos. El estudio se realizó en dos etapas. En la primera etapa se utilizaron 72 cerdos castrados en crecimiento de $30 \pm 0.5 \mathrm{~kg}$, en un arreglo factorial $2 \times 3$ : dos niveles de lisina sintética ( 0 y $2.70 \mathrm{~g} / \mathrm{kg}$ ) y tres niveles de harina de pijiguao $(0,160$ y $320 \mathrm{~g} / \mathrm{kg})$. En la segunda etapa se utilizaron 16 cerdos en engorde de $67.25 \pm 1.17 \mathrm{~kg}$, en un arreglo factorial $2 \times 2$ : dos niveles de lisina sintética $(0$ y $2.70 \mathrm{~g} / \mathrm{kg}$ ) y dos niveles de pijiguao $(0$ y $175 \mathrm{~g} / \mathrm{kg}$ ). Se determinaron las concentraciones séricas de triacilgliceroles, colesterol total y ácidos grasos. Resultados. Los cerdos en crecimiento que consumieron pijiguao presentaron menores $(p<0.001)$ concentraciones de colesterol que el grupo control (2.27 y $2.23 \mathrm{mmol} / \mathrm{l}$ vs $2.56 \mathrm{mmol} / \mathrm{l})$ y triacilgliceroles $(0.34$ y $0.28 \mathrm{mmol} / \mathrm{l}$ vs $0.42 \mathrm{mmol} / \mathrm{l})$. El ácido oleico incrementó $(\mathrm{p}<0.01)$ con el mayor nivel de pijiguao $(20.78 \%$ a $28.84 \%)$, y la lisina aumentó $(p<0.05)$ el ácido linoleico $(27.83 \%$ a $31.29 \%)$. Los cerdos alimentados con pijiguao y lisina mostraron menor $(p<0.001)$ ácido palmítico que el grupo con pijiguao sin lisina $(0.23$ y $0.19 \%$ vs 0.45 y $0.62 \%$, respectivamente). En la etapa de engorde los triacilgliceroles disminuyeron $(p<0.05)$ en los cerdos alimentados con pijiguao y lisina $(0.46$ a $0.36 \mathrm{mmol} / \mathrm{l})$. Los cerdos alimentados con pijiguao mostraron menor ácido linoleico y mayor ácido oleico $(p<0.001)$. Conclusiones. Las dietas con pijiguao y lisina sintética no causaron efectos negativos sobre los lípidos sanguíneos de cerdos.

Palabras clave: Ácidos grasos, Bactris gasipaes, cerdo, colesterol, lisina, triglicéridos (Fuente: Agrovoc). 


\section{ABSTRACT}

Objetive. Two experiments were designed to evaluate the effect of peach palm meal and synthetic lysine on blood lipids of growing and finishing pigs. Materials and methods. In experiment 1,72 barrows of $30 \pm 0.5 \mathrm{~kg}$ were randomly allotted into a $2 \times 3$ factorial design: being the main factors levels of synthetic lysine $(0$ and $2.70 \mathrm{~g} / \mathrm{kg})$ and levels of peach palm meal $(0,160$ and $320 \mathrm{~g} / \mathrm{kg})$. In experiment 2, 16 finishing pigs of $67.25 \pm$ $1.17 \mathrm{~kg}$ were used and allotted in a $2 \times 2$ factorial design arrangement of treatments: with two levels of synthetic lysine $(0$ and $2.70 \mathrm{~g} / \mathrm{kg}$ ) and two levels of peach palm meal ( 0 and $175 \mathrm{~g} / \mathrm{kg}$ ). Serum triglycerides, total cholesterol and fatty acid profile were determined. Results. In experiment 1 , growing pigs fed with 160 and $320 \mathrm{~g} / \mathrm{kg}$ of peach palm showed lower $(p<0.001)$ cholesterol $(2.27$ and $2.23 \mathrm{mmol} / \mathrm{l}$, respectively) than the control (2.56 $\mathrm{mmol} / \mathrm{l})$. The levels of triglycerides were also lower in pigs fed with 160 and $320 \mathrm{~g} / \mathrm{kg}(0.34$ and $0.28 \mathrm{mml} / \mathrm{l})$ than control group $(0.42 \mathrm{mmol} / \mathrm{l})$. Oleic acid concentration increased $(p<0.01)$ in pigs that received the highest level of peach palm $(320 \mathrm{~g} / \mathrm{kg})$ with respect to the control group $(20.78 \%$ to $28.84 \%)$ and synthetic lysine increased $(p<0.05)$ linoleic acid $(27.83 \%$ to $31.29 \%)$. Pigs fed peach palm and lysine had lower $(p<0.001)$ palmitic acid concentration than the group fed pijiguao without lysine $(0.23 \%$ and $0.19 \%$ vs $0.45 \%$ and $0.62 \%$, respectively). In experiment 2 , triglycerides decreased $(p<0.05)$ in pigs that received lysine and peach palm $(0.46$ to $0.36 \mathrm{mmol} / \mathrm{l})$. Pigs fed with peach palm had lower linoleic acid and higher oleic acid $(p<0.001)$. Conclusions. Diets with peach palm and synthetic lysine do not elicit detrimental effects on blood lipid profile in pigs.

Key words: Bactris gasipaes, cholesterol, fatty acids, lysine, pig, triglycerides. (Source: Agrovoc).

\section{INTRODUCCIÓN}

La palma de pijiguao (Bactris gasipaes Kunth) es un cultivo no tradicional perteneciente a la familia Aracaceae, es originaria del trópico húmedo (1), y se le conoce en otros países como pupunha (Brasil), peach palm (Trinidad y Tobago), pejibaye (Costa Rica), chonta (Bolivia) y chontaduro (Colombia). Del fruto del pijiguao se obtiene la harina (pericarpio y almendra), cuya composición química la califica como una excelente fuente de energía en dietas para humanos y animales (1), obteniéndose resultados satisfactorios cuando se ha utilizado en la alimentación de aves (2) y cerdos (3-5), especies de interés zootécnico para la producción de proteína de origen animal para consumo humano.

La palma de pijiguao, se utiliza artesanalmente en algunas regiones indígenas de la Amazonia, por lo que el conocimiento de su composición y efectos sobre la respuesta animal al incluirla como materia prima alternativa en las dietas para la alimentación animal, sería de gran utilidad en varios países tropicales.
La harina de pijiguao contiene $12.58 \%$ de grasa (6) y el aceite extraído de los frutos enteros de pijiguao contiene $52 \%$ de ácido oleico y es deficiente en ácido linoleico (7). El consumo de ácido oleico se ha asociado con disminución en la concentración del colesterol total, los triacilgliceroles y las lipoproteínas de alta densidad (8). Por otra parte, aunque la harina de pijiguao contiene aproximadamente entre 24 y $42 \%$ de ácido palmítico (9), se ha demostrado que el consumo de este ácido graso no eleva las concentraciones de colesterol plasmático si se encuentra en proporciones adecuadas conjuntamente con ácidos grasos insaturados (10). La harina de pijiguao contiene bajos niveles de ácido mirístico y láurico, los cuales han sido relacionados con efectos hipercolesterolémicos en humanos (11).

Se ha señalado que puede existir relación entre los lípidos sanguíneos y la calidad de la carne producida en cerdos (12). En tal sentido, la harina de pijiguao es un ingrediente energético que amerita ser evaluado en esta especie, ya que los efectos metabóli- 
cos se deben principalmente al consumo de grasas y dependiendo de la fuente lipídica de la dieta, y más específicamente del perfil de ácidos grasos que ésta contenga, los efectos serán más acentuados (13). Adicionalmente, se ha sugerido, que la harina de pijiguao puede ser incluida en grandes proporciones en las dietas para animales, si se cubren las necesidades de los aminoácidos limitantes (1), como la lisina en forma sintética, para disminuir el exceso de proteína (4).

La evidencia científica destaca la composición química de la harina del fruto de pijiguao $(1,7)$, su contenido de ácidos grasos (9) y su uso como ingrediente energético, sin afectar la ganancia de peso (4), las características de la canal (5) y las variables hematológicas y peso de órganos en cerdos (14). No obstante, no se ha reportado el efecto de este ingrediente alternativo sobre los lípidos sanguíneos de esta especie. En tal sentido, estos estudios se condujeron para evaluar el efecto de la harina de pijiguao y la lisina sintética sobre los lípidos sanguíneos de cerdos en crecimiento y engorde.

\section{MATERIALES Y MÉTODOS}

Instalaciones y animales. El estudio se realizó en el Laboratorio Sección Porcinos de la Facultad de Agronomía de la Universidad Central de Venezuela (UCV) en Maracay, estado Aragua, el cual está ubicado a 6736'36" longitud Este, $10^{\circ} 16^{\prime} 20^{\prime \prime}$ latitud Norte y 443 m.s.n.m, con una temperatura media de $25.1^{\circ} \mathrm{C}$ y una pluviosidad promedio anual de $1063 \mathrm{~mm}$. Los cerdos fueron alojados en corrales de piso sólido con dimensiones de $4.0 \mathrm{~m}^{2}$ cada uno y provistos de un comedero y un bebedero para suministro de alimento y agua ad libitum. La duración de cada estudio fue de 42 y 35 días para las etapas de crecimiento y engorde, respectivamente. Todos los cerdos utilizados fueron machos castrados del cruce de las razas Yorkshire $x$ Landrace provenientes de una granja comercial. En la etapa de crecimiento, se utilizaron 72 cerdos con un peso inicial de $30 \pm 0.5 \mathrm{~kg}$ y una edad promedio de 67 días. En la etapa de engorde, se utilizaron
16 cerdos con un peso vivo promedio inicial de $67.25 \pm 1.17 \mathrm{~kg}$ y de 107 días de edad.

Obtención de la harina de pijiguao. LoS frutos maduros enteros de la palma de pijiguao (pericarpio y almendra), fueron obtenidos y procesados de acuerdo a procedimientos descritos anteriormente (4) para obtener la harina cuya composición química, incluyendo el perfil de ácidos grasos, se presenta en la tabla 1.

Tabla 1. Composición química de la harina de pijiguao (Bactris gasipaes Kunth).

\begin{tabular}{lc}
\hline Variable & $\mathbf{g / k g}$ \\
\hline Materia seca & 920.10 \\
Proteína cruda & 80.80 \\
Lisina total & 2.60 \\
Grasa cruda & 138.90 \\
Energía bruta MJ/kg & 19.10 \\
Ácidos grasos & $\%$ de área \\
Láurico & 3.60 \\
Mirístico & 1.80 \\
Palmítico & 32.84 \\
Palmitoleico & 7.40 \\
Esteárico & 1.86 \\
Oleico & 40.93 \\
Linoleico & 9.16 \\
Linolénico & 2.46 \\
Ácidos grasos saturados & 40.10 \\
Ácidos grasos monoinsaturados & 48.33 \\
Ácidos grasos poliinsaturados & 11.62 \\
\hline
\end{tabular}

Dietas experimentales. Las dietas experimentales han sido descritas previamente (4-5) y fueron formuladas de acuerdo a las necesidades nutricionales sugeridas para cerdos en ambas etapas (15). En la etapa de crecimiento, los cerdos fueron distribuidos a uno de seis tratamientos empleando un diseño completamente al azar con arreglo factorial de tratamientos $2 \times 3$ : dos niveles de lisina sintética en la forma de L-lisina $\mathrm{HCl}(0$ y $2.70 \mathrm{~g} / \mathrm{kg}$ ) y tres niveles de harina de pijiguao $(0,160$ y $320 \mathrm{~g} / \mathrm{kg})$. La cantidad total de harina de pijiguao incluida en estas proporciones se obtuvo al sustituir el $25 \%$ y $50 \%$ de la energía digestible (ED) de $14.75 \mathrm{MJ} / \mathrm{kg}$ aportada por el maíz (15) por la ED de la harina de pijiguao de 15.94 $\mathrm{MJ} / \mathrm{kg}$ según González et al (3). Para reemplazar las proporciones de energía del maíz por la harina de pijiguao, se tomó como re- 
ferencia el estudio realizado en cerdos por Murillo (16). Se establecieron cuatro repeticiones por dieta y tres cerdos por unidad experimental.

En la etapa con cerdos de engorde se derivó un arreglo factorial 2x2: dos niveles de lisina sintética ( 0 y $2.70 \mathrm{~g} / \mathrm{kg}$ ) y dos niveles de harina de pijiguao ( 0 y $175 \mathrm{~g} / \mathrm{kg}$ ), con cuatro repeticiones por dieta y un cerdo por unidad experimental. Las dietas fueron isoenergéticas y con el mismo contenido de lisina de acuerdo a lo recomendado (15), tal como se evidencia en las tablas 2 y 3 . La harina de pijiguao y las dietas experimentales fueron analizadas para determinar su composición química de acuerdo a los procedimientos descritos por la AOAC (17).

\section{Obtención de muestras sanguíneas} y análisis químicos. Se extrajeron muestras de sangre de la vena yugular externa de cada cerdo al inicio y al final de cada etapa, entre las 08:00 y 10:00 $h$, después de haber colocado el alimento en los comederos. Para la obtención de la muestra, se utilizaron jeringas estériles con agujas de $21 \mathrm{G} \times 1$ 1/2" y tubos al vacío de $5 \mathrm{ml}$ sin anticoagulante. Las muestras

Tabla 2. Composición química y contenido de ácidos grasos de las dietas para cerdos en etapa de crecimiento.

\begin{tabular}{|c|c|c|c|c|c|c|}
\hline \multirow{2}{*}{$\begin{array}{l}\text { Lisina } \\
\text { Sintética }{ }^{1} \\
\text { Harina de } \\
\text { Pijiguao }^{2}\end{array}$} & \multicolumn{3}{|c|}{0} & \multicolumn{3}{|c|}{2.70} \\
\hline & $\mathbf{0}$ & 160 & 320 & $\mathbf{0}$ & 160 & 320 \\
\hline \multicolumn{7}{|c|}{ Composición (g/kg) } \\
\hline Proteína cruda & 182.9 & 182.8 & 180.6 & 158.0 & 157.7 & 158.4 \\
\hline Lisina total & 9.80 & 9.60 & 9.70 & 9.60 & 9.50 & 9.80 \\
\hline $\begin{array}{l}\text { Extracto } \\
\text { etéreo }\end{array}$ & 57.2 & 55.7 & 59.6 & 64.0 & 65.0 & 57.6 \\
\hline $\mathrm{ED} \mathrm{MJ} / \mathrm{kg}^{3}$ & 14.5 & 14.5 & 14.6 & 14.5 & 14.5 & 14.6 \\
\hline \multicolumn{7}{|c|}{ Ácidos grasos (\% de área) } \\
\hline Palmítico & 0.20 & 1.20 & 1.26 & 0.47 & 0.73 & 0.80 \\
\hline Palmitoleico & 23.49 & 24.27 & 33.92 & 27.69 & 28.60 & 25.62 \\
\hline Oleico & 33.89 & 36.64 & 36.95 & 37.66 & 38.22 & 39.38 \\
\hline Linoleico & 41.39 & 36.82 & 27.06 & 32.66 & 31.00 & 31.93 \\
\hline Linolénico & 1.03 & 1.07 & 0.81 & 1.52 & 1.45 & 2.27 \\
\hline
\end{tabular}

${ }^{1} \mathrm{~L}$-Lisina $\mathrm{HCl}$ (78\% lisina) en $\mathrm{g} / \mathrm{kg}$ añadida a expensas de harina de soya (46.5\% PC); ${ }^{2}$ Valores obtenidos en $\mathrm{g} / \mathrm{kg}$ al sustituir el $25 \%$ y $50 \%$ de la energía digestible (ED) de 14.75 $\mathrm{MJ} / \mathrm{kg}$ aportada por el maíz (15) por la ED de la harina de pijiguao de $15.94 \mathrm{MJ} / \mathrm{kg}$ según González et al (3); ${ }^{3}$ Valor calculado.
Tabla 3. Composición química de las dietas para cerdos en etapa de engorde.

\begin{tabular}{lcccc}
\hline Lisina Sintética $^{1}$ & \multicolumn{2}{c}{$\mathbf{0}$} & \multicolumn{2}{c}{$\mathbf{2 . 7 0}$} \\
\cline { 2 - 5 } Harina de Pijiguao $^{2}$ & $\mathbf{0}$ & $\mathbf{1 7 5}$ & $\mathbf{0}$ & $\mathbf{1 7 5}$ \\
\hline Composición (g/kg) & & & & \\
$\quad$ Proteína Cruda & 156.3 & 123.9 & 159.4 & 126.7 \\
$\quad$ Lisina total & 7.5 & 7.7 & 7.8 & 7.7 \\
Extracto etéreo & 47.4 & 57.5 & 44.6 & 51.0 \\
$\quad$ ED MJ/kg ${ }^{3}$ & 14.5 & 14.5 & 14.5 & 14.5 \\
Ácidos grasos (\% de área) & & & \\
$\quad$ Palmítico & 1.32 & 1.49 & 1.13 & 1.73 \\
$\quad$ Palmitoleico & 30.80 & 32.00 & 31.87 & 32.09 \\
Oleico & 40.03 & 40.00 & 41.00 & 43.00 \\
$\quad$ Linoleico & 27.09 & 25.00 & 25.80 & 22.00 \\
Linolénico & 0.76 & 1.51 & 0.20 & 1.18 \\
\hline
\end{tabular}

${ }^{1} \mathrm{~L}$-Lisina $\mathrm{HCl}$ (78\% lisina) en $\mathrm{g} / \mathrm{kg}$ añadida a expensas de harina de soya (46.5\% PC); ${ }^{2}$ Valores obtenidos en $\mathrm{g} / \mathrm{kg}$ al sustituir el $25 \%$ de la energía digestible (ED) de $14.75 \mathrm{MJ} / \mathrm{kg}$ aportada por el maíz (15) por la ED de la harina de pijiguao de $15.94 \mathrm{MJ} / \mathrm{kg}$ según González et al (3); ${ }^{3}$ Valor calculado.

fueron transportadas al Laboratorio de Patología Clínica de la Facultad de Ciencias Veterinarias de la UCV, donde fueron centrifugadas a $1500 \mathrm{~g} \times 10$ minutos a $4^{\circ} \mathrm{C}$ para obtener el suero sanguíneo que fue almacenado a $-20^{\circ} \mathrm{C}$ hasta su utilización.

Las concentraciones séricas de colesterol total y triacilgliceroles se determinaron empleando los métodos enzimáticos-espectrofotométricos propuestos por Allain et al (18) y Bucolo y Harold (19), respectivamente. El perfil de ácidos grasos en la harina de pijiguao, en las dietas experimentales y en el suero sanguíneo se determinó según la metodología de Morrison y Smith (20) utilizando un cromatógrafo de gases AGILENT 6820, equipado con detector de ionización de llama. El equipo estaba provisto de una columna empacada con $15 \%$ de succinato de dietilenglicol (DEGS) sobre Chromosorb Wiaw, 80/100, 2 m, SST, 1/8" od $\times 2 \mathrm{~mm}$ id, empleando nitrógeno a 30 $\mathrm{ml} /$ minuto como gas de arrastre. La temperatura de la columna durante los primeros 5 minutos fue de $250^{\circ} \mathrm{C}$ y la del inyector de $230^{\circ} \mathrm{C}$. Se inyectaron $2 \mu \mathrm{l}$ de cada mezcla de ácidos grasos metilados, los cuales fueron identificados por sus tiempos de retención en comparación con los correspondientes patrones. 
Análisis estadístico. Los datos obtenidos para cada variable estudiada fueron analizados utilizando el programa SAS (21) a través de PROC MIXED, empleando un modelo estadístico que incluyó los efectos simples y de la interacción entre los dos factores, harina de pijiguao y la lisina sintética, sobre el colesterol total, triacilgliceroles y perfil de ácidos grasos. Se realizaron contrastes utilizando una prueba de $\mathrm{t}$ de Student para comparar las medias de los diferentes tratamientos que se expresaron conjuntamente con sus respectivos errores estándar. Cuando las variables estudiadas resultaron significativamente diferentes $(p<0.05)$ por efectos simples de los factores conjuntamente con los efectos de la interacción entre éstos, solo se discutieron estos últimos que corresponden al efecto de las dietas experimentales.

\section{RESULTADOS}

Cerdos en crecimiento. Los lípidos sanguíneos de los cerdos alimentados con harina de pijiguao en la etapa de crecimiento variaron significativamente $(p<0.001)$ al compararse con el grupo control (Tabla 4). Los cerdos que consumieron las dietas con 160 y $320 \mathrm{~g} / \mathrm{kg}$

Tabla 4. Efectos simples de la harina de pijiguao (Bactris gasipaes Kunth) y lisina sintética sobre la concentración y composición de los lípidos sanguíneos de cerdos en etapa de crecimiento.

\begin{tabular}{|c|c|c|c|c|c|c|c|}
\hline & \multicolumn{4}{|c|}{ Harina de pijiguao ${ }^{1}$} & \multicolumn{3}{|c|}{ Lisina sintética ${ }^{2}$} \\
\hline & $\mathbf{0}$ & 160 & 320 & EE $^{3}$ & $\mathbf{0}$ & 2.70 & $\mathrm{EE}^{3}$ \\
\hline $\begin{array}{l}\mathrm{CT} \\
(\mathrm{mmol} / \mathrm{l})\end{array}$ & $2.56^{a}$ & $2.27^{\mathrm{b}}$ & $2.23^{\mathrm{b}}$ & 0.05 & 2.31 & 2.40 & 0.04 \\
\hline $\begin{array}{l}\text { TAG } \\
(\mathrm{mmol} / \mathrm{l})\end{array}$ & $0.42^{\mathrm{a}}$ & $0.34^{b}$ & $0.28^{\mathrm{b}}$ & 0.02 & 0.32 & 0.35 & 0.01 \\
\hline \multicolumn{8}{|c|}{ Ácidos grasos (\% de área) ${ }^{4}$} \\
\hline Palmítico & $0.17^{\mathrm{a}}$ & $0.34^{b}$ & $0.41^{\mathrm{b}}$ & 0.02 & $0.41^{\mathrm{a}}$ & $0.20^{\mathrm{b}}$ & 0.02 \\
\hline Palmitoleico & 47.81 & 44.87 & 41.22 & 2.81 & 47.57 & 41.70 & 2.30 \\
\hline Esteárico & 0.99 & 0.94 & 0.44 & 0.28 & 0.91 & 0.68 & 0.23 \\
\hline Oleico & $20.78^{a}$ & $24.49^{a}$ & $28.84^{\mathrm{b}}$ & 1.34 & 23.28 & 26.13 & 1.09 \\
\hline Linoleico & 30.24 & 29.36 & 29.10 & 1.78 & $27.83^{a}$ & $31.29^{b}$ & 1.45 \\
\hline AGS & 1.17 & 1.28 & 0.85 & 0.29 & 1.32 & 0.88 & 0.23 \\
\hline AGM & 68.60 & 69.36 & 70.06 & 1.45 & 70.85 & 67.83 & 1.18 \\
\hline AGP & 30.24 & 29.36 & 29.10 & 1.78 & $27.83^{\mathrm{a}}$ & $31.29^{\mathrm{b}}$ & 1.45 \\
\hline
\end{tabular}

${ }^{1} \mathrm{~L}$-Lisina $\mathrm{HCl}$ (78\% lisina) en $\mathrm{g} / \mathrm{kg}$ añadida a expensas de harina de soya (46.5\% PC). ${ }^{2}$ Valores obtenidos en $\mathrm{g} / \mathrm{kg}$ al sustituir el $25 \%$ y $50 \%$ de la energía digestible (ED) de $14.75 \mathrm{MJ} / \mathrm{kg}$ aportada por el maíz (15) por la ED de la harina de pijiguao de $15.94 \mathrm{MJ} / \mathrm{kg}$ según González et al (3). ${ }^{3} \mathrm{EE}=$ Error estándar. ab Letras distintas en la misma fila para un factor indican diferencias significativas: Efecto de la harina de pijiguao sobre colesterol total $(C T)$, triacilgliceroles $(T A G)$, ácido palmítico $(p<0.001)$ y oleico $(p<0.01)$; y de lisina sintética sobre ácido linoleico $(p<0.05)$ y palmítico $(p<0.001) .{ }^{4} A G S=$ Ácidos grasos saturados; $A G M=$ Ácidos grasos monoinsaturados; $A G P=$ Ácidos grasos poliinsaturados. harina de pijiguao presentaron disminución $(p<0.001)$ en la concentración de colesterol total con respecto al grupo que no consumió harina de pijiguao. De igual manera, las concentraciones de triacilgliceroles fueron menores $(p<0.001)$ en los cerdos alimentados con harina de pijiguao a ambos niveles al compararse con el grupo control. No se observó efecto de este ingrediente sobre el total de ácidos grasos saturados (AGS), monoinsaturados (AGM), o poliinsaturados (AGP), no obstante, se evidenciaron variaciones en los ácidos grasos individualmente. En tal sentido, la concentración del ácido oleico, fue mayor $(p<0.01)$ en los cerdos alimentados con 320 $\mathrm{g} / \mathrm{kg}$ harina de pijiguao al compararse con el grupo de cerdos bajo el tratamiento con $160 \mathrm{~g} / \mathrm{kg}$ y las dietas sin harina de pijiguao $(p<0.01)$. Además, la concentración de ácido palmítico aumentó significativamente $(p<0.001)$ en los cerdos alimentados con los dos niveles de harina de pijiguao, con respecto al grupo de cerdos alimentados con las dietas sin este ingrediente, y se redujo en los cerdos alimentados con lisina sintética $(p<0.001)$.

Por otra parte, la lisina sintética aumentó $(p<0.05)$, los AGP, representados por el ácido linoleico independientemente de la adición de harina de pijiguao, y sin evidencia de efectos significativos sobre las concentraciones de colesterol total y triacilgliceroles. El efecto de la interacción (efecto de dieta) entre los dos factores estudiados (Tabla 5), indicó que los cerdos alimentados con harina de pijiguao a ambos niveles con lisina sintética presentaron menores $(p<0.001)$ concentraciones de ácido palmítico en comparación con los cerdos que consumieron harina de pijiguao sin lisina, pero fueron similares al grupo de la dieta control. No se observaron variaciones significativas entre dietas para el resto de los ácidos grasos, el colesterol total y los triacilgliceroles (Tabla 5).

Cerdos en engorde. En la etapa de engorde (Tabla 6), las concentraciones séricas de triacilgliceroles disminuyeron en los cerdos alimentados, tanto con harina de pijiguao $(p<0.01)$ como con lisina sintética $(p<0.01)$, y la interacción entre ambos factores redujo $(p<0.05)$ 
Tabla 5. Efectos de la interacción de la harina de pijiguao (Bactris gasipaes Kunth) y lisina sintética sobre la concentración y composición de los lípidos sanguíneos de cerdos en etapa de crecimiento.

\begin{tabular}{|c|c|c|c|c|c|c|c|}
\hline \multirow{2}{*}{$\begin{array}{l}\text { Lisina } \\
\text { sintética }^{1} \\
\text { Harina de } \\
\text { Pijiguao }^{2}\end{array}$} & \multicolumn{3}{|c|}{0} & \multicolumn{3}{|c|}{2.70} & \multirow[b]{2}{*}{$\mathrm{EE}^{3}$} \\
\hline & $\mathbf{0}$ & 160 & 320 & 0 & 160 & 320 & \\
\hline $\mathrm{CT}(\mathrm{mmol} / \mathrm{l})$ & 2.53 & 2.19 & 2.20 & 2.59 & 2.35 & 2.25 & 0.08 \\
\hline TAG (mmol/l) & 0.39 & 0.31 & 0.28 & 0.45 & 0.32 & 0.35 & 0.02 \\
\hline \multicolumn{8}{|c|}{ Ácidos grasos (\% de área) ${ }^{4}$} \\
\hline Palmítico & $0.16^{\mathrm{a}}$ & $0.45^{b}$ & $0.62^{\mathrm{b}}$ & $0.19^{\mathrm{a}}$ & $0.23^{\mathrm{a}}$ & $0.19^{\mathrm{a}}$ & 0.03 \\
\hline Palmitoleico & 51.11 & 47.30 & 44.30 & 44.53 & 42.44 & 48.14 & 3.15 \\
\hline Esteárico & 1.39 & 0.78 & 0.52 & 0.60 & 1.11 & 0.33 & 0.39 \\
\hline Oleico & 18.36 & 23.68 & 27.80 & 23.21 & 25.31 & 29.87 & 1.90 \\
\hline Linoleico & 28.99 & 27.80 & 26.72 & 31.49 & 30.92 & 31.48 & 2.11 \\
\hline AGS & 1.55 & 1.23 & 1.19 & 0.79 & 1.34 & 0.51 & 0.41 \\
\hline AGM & 69.47 & 70.97 & 72.10 & 67.74 & 67.75 & 68.02 & 2.05 \\
\hline AGP & 28.99 & 27.80 & 26.72 & 31.49 & 30.92 & 31.48 & 2.11 \\
\hline
\end{tabular}

${ }^{1} \mathrm{~L}$-Lisina $\mathrm{HCl}\left(78 \%\right.$ lisina) en $\mathrm{g} \mathrm{kg}^{-1}$ añadida a expensas de harina de soya (46.5\% PC); ${ }^{2}$ Valores obtenidos en $\mathrm{g} \mathrm{kg}^{-1}$ al sustituir el $25 \%$ y $50 \%$ de la energía digestible (ED) de $14.75 \mathrm{MJ} \mathrm{kg}^{-1}$ aportada por el maíz (15) por la ED de la harina de pijiguao de $15.94 \mathrm{MJ} \mathrm{kg}^{-1}$ según González et al (3); ${ }^{3} \mathrm{EE}=$ Error estándar; ${ }^{\mathrm{ab}}=$ Letras distintas en la misma fila indican diferencias significativas $(p<0.001)$. Sin efectos sobre los triacilgliceroles (TAG) y colesterol total (CT). ${ }^{4} \mathrm{AGS}=$ Ácidos grasos saturados; $\mathrm{AGM}=$ Ácidos grasos monoinsaturados; $\mathrm{AGP}=$ Ácidos grasos poliinsaturados.

Tabla 6. Efectos simples de la harina de pijiguao (Bactris gasipaes Kunth) y lisina sintética sobre la concentración y composición de los lípidos sanguíneos de cerdos en etapa de engorde.

\begin{tabular}{lcccccc}
\hline & \multicolumn{3}{c}{ Harina de pijiguao } & \multicolumn{3}{c}{ Lisina Sintética $^{\mathbf{1}}$} \\
\cline { 2 - 7 } & $\mathbf{0}$ & $\mathbf{1 7 5}$ & $\mathbf{E E}^{\mathbf{3}}$ & $\mathbf{0}$ & $\mathbf{2 . 7 0}$ & EE $^{\mathbf{3}}$ \\
\hline CT (mmol/I) & 2.47 & 2.55 & 0.07 & 2.49 & 2.53 & 0.07 \\
TAG (mmol/I) & $0.42^{\mathrm{a}}$ & $0.38^{\mathrm{b}}$ & 0.01 & $0.42^{\mathrm{a}}$ & $0.37^{\mathrm{b}}$ & 0.01 \\
Ácidos grasos (\% de área) & & & & \\
Palmítico & 1.14 & 1.62 & 0.21 & 1.42 & 1.35 & 0.21 \\
Palmitoleico & 34.05 & 31.91 & 1.25 & 35.30 & 30.03 & 1.25 \\
Esteárico & 0.35 & 0.36 & 0.09 & 0.27 & 0.43 & 0.09 \\
Oleico & $33.64^{\mathrm{a}}$ & $41.49^{\mathrm{b}}$ & 3.23 & $35.30^{\mathrm{a}}$ & $39.83^{\mathrm{b}}$ & 3.23 \\
Linoleico & $30.83^{\mathrm{a}}$ & $24.63^{\mathrm{b}}$ & 1.32 & 27.69 & 27.76 & 1.32 \\
\multicolumn{1}{c}{ AGS } & 1.49 & 1.98 & 0.21 & 1.69 & 1.78 & 0.21 \\
\multicolumn{1}{c}{ AGM } & $67.68^{\mathrm{a}}$ & $73.40^{\mathrm{b}}$ & 1.34 & 70.62 & 70.46 & 1.34 \\
\multicolumn{1}{c}{ AGP } & $30.83^{\mathrm{a}}$ & $24.63^{\mathrm{b}}$ & 1.32 & 27.69 & 27.76 & 1.32 \\
\hline
\end{tabular}

${ }^{1} \mathrm{~L}$-Lisina $\mathrm{HCl}$ (78\% lisina) en $\mathrm{g} / \mathrm{kg}$ añadida a expensas de harina de soya (46.5\% PC); ${ }^{2}$ Valores obtenidos en $\mathrm{g} / \mathrm{kg}$ al sustituir el $25 \%$ la energía digestible (ED) de $14.75 \mathrm{MJ} / \mathrm{kg}$ aportada por el maíz (15) por la ED de la harina de pijiguao de $15.94 \mathrm{MJ} / \mathrm{kg}$ según González et al (3); ${ }^{3} \mathrm{EE}=$ Error estándar. ${ }^{\mathrm{ab}}=$ Letras distintas en la misma fila para cada factor indican diferencias significativas: Efectos de la harina de pijiguao sobre triacilgliceroles (TAG) y AGM $(p=0.01)$, ácidos linoleico y oleico $(p<0.001)$ y de lisina sintética sobre el acido oleico $(p=0.05)$ y TAG $(p<0.01)$. Sin efectos sobre colesterol total $(\mathrm{CT}) ;{ }^{4} \mathrm{AGS}=$ Ácidos grasos saturados; $\mathrm{AGM}=$ Ácidos grasos monoinsaturados y $\mathrm{AGP}=$ Ácidos grasos poliinsaturados. los valores de esta variable (Tabla 7), al compararse con el valor mostrado por el grupo de cerdos de la dieta control $(p<0.05)$. Por el contrario, las concentraciones de colesterol total fueron similares entre grupos. Con respecto a los ácidos grasos (Tabla 6), se observó un incremento significativo en la proporción correspondiente al ácido oleico en los cerdos alimentados con harina de pijiguao $(p<0.001)$ o la lisina sintética $(p<0.05)$ al compararse con los grupos sin harina de pijiguao o sin lisina sintética.

Por otra parte, los cerdos alimentados con harina de pijiguao mostraron menor proporción de ácido linoléico $(p<0.001)$ dentro del grupo de los ácidos grasos poliinsaturados (AGP). No se observaron efectos significativos de las dietas sobre el perfil de los ácidos grasos evaluados (Tabla 7).

Tabla 7. Efectos de la interacción entre harina de pijiguao (Bactris gasipaes Kunth) y lisina sintética sobre la concentración y composición de los lípidos sanguíneos de cerdos en etapa de engorde.

\begin{tabular}{lrrrrr}
\hline $\begin{array}{l}\text { Lisina Sintética } \\
\text { Harina de } \\
\text { Pijiguao }^{2}\end{array}$ & \multicolumn{3}{c}{$\mathbf{0}$} & \multicolumn{3}{c}{$\mathbf{2 . 7 0}$} \\
\cline { 2 - 6 } & $\mathbf{0}$ & $\mathbf{1 7 5}$ & $\mathbf{0}$ & $\mathbf{1 7 5}$ & EE $^{3}$ \\
\hline CT (mmol/l) & 2.47 & 2.52 & 2.46 & 2.59 & 0.10 \\
TAG (mmol/l) & $0.46^{\mathrm{a}}$ & $0.39^{\mathrm{b}}$ & $0.37^{\mathrm{b}}$ & $0.36^{\mathrm{b}}$ & 0.01 \\
Ácidos grasos (\% de área) & & & & \\
Palmítico & 1.26 & 1.58 & 1.03 & 1.66 & 0.29 \\
Palmitoleico & 36.41 & 34.23 & 31.69 & 29.58 & 4.52 \\
Esteárico & 0.17 & 0.38 & 0.52 & 0.34 & 0.13 \\
Oleico & 30.72 & 39.89 & 36.56 & 43.09 & 2.17 \\
Linoleico & 31.46 & 23.93 & 30.20 & 25.32 & 1.86 \\
$\quad$ AGS & 1.43 & 1.95 & 1.55 & 2.01 & 0.30 \\
$\quad$ AGM & 67.12 & 74.12 & 68.25 & 72.67 & 1.90 \\
$\quad$ AGP & 31.46 & 23.93 & 30.20 & 25.32 & 1.86 \\
\hline
\end{tabular}

${ }^{1} \mathrm{~L}$-Lisina $\mathrm{HCl}$ (78\% lisina) en $\mathrm{g} / \mathrm{kg}$ añadida a expensas de harina de soya (46.5\% PC); ${ }^{2}$ Valores obtenidos en $\mathrm{g} / \mathrm{kg}$ al sustituir el $25 \%$ de la energía digestible (ED) de $14.75 \mathrm{MJ} / \mathrm{kg}$ aportada por el maíz (15) por la ED de la harina de pijiguao de $15.94 \mathrm{MJ} / \mathrm{kg}$ según González et $\mathrm{al}(3) ;{ }^{3} \mathrm{EE}=$ Error estándar. ${ }^{\mathrm{ab}}=$ Letras distintas en la misma fila indican diferencias significativas $(p<0.05)$ para triacilgliceroles (TAG), sin efectos sobre colesterol total (CT); AGS=Ácidos grasos saturados; $A G M=A ́ c i d o s$ grasos monoinsaturados; $\mathrm{AGP}=$ Ácidos grasos poliinsaturados.

\section{DISCUSIÓN}

Las concentraciones de colesterol total y triacilgliceroles para cerdos en crecimiento y engorde, se ubicaron dentro de los valores de referencia señalados por Dubreuil y 
Lapierre (22), quienes reportaron un rango de $2.46-2.56 \mathrm{mmol} / \mathrm{l}$ y $0.36-0.42 \mathrm{mmol} / \mathrm{l}$ para colesterol y triacilgliceroles, respectivamente.

La reducción en las concentraciones séricas de colesterol total y triacilgliceroles se ha asociado al consumo de ácido oleico en humanos (8). Este ácido graso se encuentra en un $40.93 \%$ en la harina de pijiguao utilizada en el presente estudio, valor que se aproxima al encontrado en una de las variedades de pijiguao evaluadas en Brasil de $42.80 \%$ (9). En tal sentido, la proporción de ácido oleico presente en la harina de pijiguao permite sustentar la respuesta de menores concentraciones de colesterol y triacilgliceroles de los cerdos en crecimiento alimentados con este ingrediente. Aunque no existen evidencias previas referentes a los efectos de la harina de pijiguao sobre los lípidos sanguíneos en cerdos, se han evaluado los efectos del extracto acuoso del fruto de pijiguao sobre el metabolismo de ratas jóvenes (23), observándose una disminución en los niveles de triacilgliceroles, lo cual es coincidente con los resultados aquí obtenidos.

Por el contrario, en ese mismo estudio (23), se encontró un incremento en las concentraciones de colesterol en las ratas evaluadas, mientras que en pollos de engorde (7), la inclusión del aceite de pijiguao en las dietas no produjo variaciones significativas en el contenido total de colesterol al compararse con otras fuentes lipídicas.

Estos resultados difieren de la respuesta observada para esta variable en los cerdos de ambas etapas, lo que podría estar relacionado a variaciones entre especies o con el procesamiento del fruto de pijiguao utilizado.

Adicionalmente, los ácidos grasos saturados como el mirístico y el láurico están relacionados con incrementos en las concentraciones de colesterol (11), no obstante, el contenido de estos ácidos grasos en la harina de pijiiguao fue relativamente bajo, por lo que al mezclarla con el resto de los ingredientes de las dietas no se detectó la presencia de los mismos, argumento válido que podría explicar la disminución en las concentraciones de colesterol encontradas en el presente estudio.

La respuesta asociada con menores concentraciones de triacilgliceroles de los cerdos alimentados con harina de pijiguao y lisina sintética en la etapa de engorde, sugiere un efecto favorable al incluir ambos ingredientes en la dieta de cerdos próximos al sacrificio. Los ácidos grasos insaturados, como el ácido oleico, presente en relativamente alta proporción en las dietas con harina de pijiguao, se han relacionado con reducciones en las concentraciones de triacilgliceroles (24), lo que conjuntamente con la disminución de la hiperlipidemia que genera la inclusión de lisina sintética en la dieta (25), posiblemente respalda la respuesta observada de menor concentración de triacilgliceroles al incluir harina de pijiguao y lisina sintética a la dieta.

La adición de lisina sintética en la forma L-lisina $\mathrm{HCl}$ a las dietas, no produjo variaciones en las concentraciones de colesterol total en ninguna de las dos etapas, respuesta que se sustenta con resultados obtenidos previamente, que no reportaron cambios significativos en los valores de esta variable al incrementar el contenido de lisina añadiendo L-lisina $\mathrm{HCl}$ en las dietas para cerdas (26).

De manera similar, en un estudio conducido para determinar la eficacia de dos fuentes de lisina sintética (L-lisina $\mathrm{HCl}$ y L-lisina sulfato) en la dieta de pollos, no se reportaron variaciones en los valores séricos de colesterol total (27).

Las variaciones en los valores sanguíneos de los ácidos grasos pueden atribuirse al contenido de los mismos en los ingredientes utilizados, ya que se ha determinado que los ácidos grasos presentes en la dieta, influyen directamente sobre los lípidos sanguíneos (24). En tal sentido, es posible explicar el incremento del ácido oleico al añadir $320 \mathrm{~g} / \mathrm{kg}$ y $175 \mathrm{~g} / \mathrm{kg}$ de harina de pijiguao en las dietas de los cerdos en crecimiento y engorde, respectivamente. 
Asimismo, la disminución de los niveles de los AGP, específicamente el ácido linoleico en este caso, en los cerdos en etapa de engorde alimentados con harina de pijiguao, podría asociarse con el menor contenido de este ácido graso en las dietas que contenían este ingrediente.

Es limitada la disponibilidad de antecedentes científicos que sustenten el resultado de la interacción encontrada entre la harina de pijiguao y lisina sintética en la dieta sobre la reducción del ácido palmítico de cerdos en la etapa crecimiento. Aunque es relativamente alta la proporción de este ácido graso en la harina de pijiguao utilizada (32.84\%), su contenido en las dietas experimentales de ambas etapas fue bajo en relación al resto de los ácidos grasos, exceptuando al ácido linolénico.

Aunque las concentraciones del ácido palmítico fueron mayores en los cerdos alimentados con harina de pijiguao sin lisina y el grupo de la dieta control, se evidencian reducciones importantes de este ácido graso en los cerdos alimentados con lisina sintética y harina de pijiguao. La lisina sintética en la forma de L-lisina $\mathrm{HCl}$, como la utilizada en el presente estudio, se ha relacionado con la reducción de la síntesis de ácido palmítico al disminuir la concentración del malonilCoA en el hígado por inhibición de la enzima acetil-CoA carboxilasa, vía proteína cinasa dependiente de AMPc (AMPK) en ratones (25), favoreciendo a su vez la entrada de los ácidos grasos a la mitocondria para su oxidación. Por otra parte, la lisina es un aminoácido esencial utilizado para la síntesis de carnitina, la cual interviene en el transporte de ácidos grasos de cadena larga a través de la membrana mitocondrial para su oxidación y posterior utilización para proveer energía (28).

La evidencia científica indica que el suministro de lisina sintética en la dieta puede aumentar la síntesis de L-carnitina y en consecuencia la B-oxidación de los ácidos grasos de cadena larga, probablemente disminuyendo su concentración en suero sanguíneo; lo que, con- comitantemente con una disminución de la síntesis del palmitato podría explicar el efecto encontrado como resultado de la interacción entre la harina de pijiguao y lisina sintética para el ácido palmítico, que se manifestó en los cerdos en crecimiento con pesos entre 30 y $67 \mathrm{~kg}$.

Los resultados indican que al incluir harina de pijiguao a las dietas es posible reducir las concentraciones séricas de triacilgliceroles y colesterol en cerdos en etapa de crecimiento, respuesta que parece ser independiente de la inclusión de lisina sintética, mientras que el consumo de este aminoácido conjuntamente con la harina de pijiguao, podría disminuir las concentraciones séricas de ácido palmítico, probablemente debido a los efectos hipolipidémicos de la lisina en forma libre.

Adicionalmente, en la etapa de engorde, el consumo de la harina de pijiguao y la lisina sintética podría disminuir las concentraciones de triacilgliceroles, probablemente como respuesta al elevado contenido de ácido oleico, cuya concentración sérica incrementa en respuesta al consumo de dietas con harina de pijiguao. De manera general, se puede afirmar que el pijiguao es un ingrediente con una relación de ácidos grasos insaturados:saturados que sugiere que es posible su incorporación a dietas para cerdos sustituyendo la energía aportada por el maíz como ingrediente energético principal, sin causar efectos negativos sobre los lípidos sanguíneos o dislipidemias.

En conclusión, las dietas con pijiguao y lisina sintética no causaron efectos negativos sobre los lípidos sanguíneos de cerdos.

\section{Agradecimiento}

Al Consejo de Desarrollo Científico y Humanístico de la Universidad Central de Venezuela ( $\mathrm{CDCH}-\mathrm{UCV}$ ) por el financiamiento concedido para la ejecución del Proyecto de Investigación: PG Nro. 11-7137-2008. 


\section{REFERENCIAS}

1. Leterme $P$, García $M$, Londoño $A$, Rojas $M$, Buldgen A, Souffrant W. Chemical composition and nutritive value of peach palm (Bactris gasipaes Kunth) in rats. J Sci Food Agric 2005; 85:1505-1521.

2. Gonzales L, Navarro D, Vásquez R. Deshidratación del Bactris gasipaes Kunth (pijuayo) por flujo de aire caliente y su empleo como sustituto del maíz en raciones para pollos parrilleros. Revista Amazónica de Investigación Alimentaria RAIA 2002; 2:67-87.

3. González C, Díaz I, Salas R. Determinación de la digestibilidad ileal aparente en cerdos de la harina de pijiguao (Bactris gasipaes H.B.K.). Arch Latinoam Prod Anim 1997; 5(Supl 1):283-284.

4. Rico D, Colina J, Araque $H$, Rossini $M$, Rueda de $A E$, León $M$. Comportamiento productivo de cerdos en crecimiento alimentados con harina de pijiguao (Bactris gasipaes H.B.K.) y lisina. Rev Fac Agron (UCV) 2009; 35:49-55.

5. Colina-Rivero J, Araque-Molina $\mathrm{H}$, JerezTimaure N, Rico-Barreto D. Crecimiento y características de la canal de cerdos en engorde alimentados con harina de pijiguao (Bactris gasipaes H.B.K.) y lisina. Rev Fac Agron LUZ 2010; 27: 251-269.

6. Pizzani $\mathrm{P}$, Blanco M, Malaver T, Godoy $\mathrm{S}$, Matute I, Palma J, et al. Composición fitoquímica y nutricional de harina de pijiguao (Bactris gasipaes Kunth en H.B.K). Zootecnia Trop 2008; 26:235-238.

7. Baldizán G, Oviedo M, Michelangeli C, Vargas RE. Effects of peach palm oil on performance, serum lipoproteins and haemostasis in broilers. $\mathrm{Br}$ Poult Sci 2010; 51:784-790.
8. Lopez-Huertas E. Health effects of oleic acid and long chain omega- 3 fatty acids (EPA and DHA) enriched milks. A review of intervention studies. Pharmacol Res 2010; 61:200-207.

9. Yuyama L, Aguiar J, Yuyama K, Clement C, Macedo S, Fávaro D, et al. Chemical composition of the fruit mesocarp of three peach palm (Bactris gasipaes) populations grown in Central Amazonia, Brazil. Int J Food Sci Nutr 2003; 54:49-56.

10. French MA, Sundram K, Thomas $M$. Cholesterolaemic effect of palmitic acid in relation to other dietary fatty acids. Asia Pac J Clin Nutr 2002; 11:S401-S407.

11. German JB, Dillard CJ. Saturated fats: what dietary intake?. Am J Clin Nutr 2004; 80:550-559.

12. Casellas J, Noguera JL, Reixach J, Díaz I, Amills M, Quintanilla R. Bayes factor analyses of heritability for serum and muscle lipid traits in Duroc pigs. J Anim Sci 2010; 88:2246-54.

13. Averette Gatlin L, See MT, Hansen JA, Odle J. Hydrogenated dietary fat improves pork quality of pigs from two lean genotypes. J Anim Sci 2003; 81:1989-1997.

14. Colina J, Rossini M, Tovar C, Araque $\mathrm{H}$. Peso de órganos y parámetros hematológicos de cerdos en engorde alimentados con harina de pijiguao (Bactris gasipaes H.B.K.) y lisina. Arch Latinoam Prod Anim 2009; 17(Supl 1):175-179.

15. NRC. Nutrient Requirements of Swine, 10th ed. Washington, D.C.: National Academy Press; 1998. 
16. Murillo M. Utilización de la harina de pejibaye en la alimentación de aves y cerdos. En: Mora-Urpi J, Szott L, Murillo M, Patiño VM (eds): IV Congreso Internacional sobre Biología, Agronomía e Industrialización del Pijuayo. Iquitos, Perú. Primera edición. San José de Costa Rica: Universidad de Costa Rica; 1993.

17. AOAC. Official Methods of Analysis. 15th ed. Arlington, VA: Association of Official Analytical Chemists; 1990.

18. Allain ChC, Poon LS, Chan CSG, Richmond W, Fu PC. Enzymatic Determination of Total Serum Cholesterol. Clin Chem 1974; 20: 470-475.

19. Bucolo G, Harold D. Quantitative Determination of Serum Triglycerides by the Use of Enzymes. Clin Chem 1973; 19: 476-482.

20. Morrison WR, Smith ML. Preparation of fatty acid methyl ester and dymethylacetals from lipids with boron fluoride-methanol. J Lipid Res 1964; 53: 600-608.

21. Statistical Analysis System (SAS 9.1). SAS Institute Inc., SAS 9.1, Cary, NC: 2004. [Citado 2009 Dic 12]. URL disponible en: URL:http://support.sas. com/documentation/onlinedoc/91pdf/ index.html.

22. Dubreuil $\mathrm{P}$, Lapierre $\mathrm{H}$. Biochemistry reference values for Quebec lactating dairy cows, nursing sows, growing pigs and calves. Can J Vet Res 1997; 61:235-239.

23. Gómez G, Quesada S, Nanne C. Efecto de factores antinutricionales en el pejibaye (Bactris gasipaes) sobre el metabolismo de ratas jóvenes. Agronomía Costarricense 1998; 22:191-198.
24. Salajpal K, Karolyi D, Dikić M, Kantura V, Kiš G, Sinjer Ž. Influence of acorn intake on blood lipid profile and longisimus muscle characteristics of black slavonian pig. Acta Agric Slov 2008; (Supl 2): 99-105.

25. Hirabayashi $Y$, Murakami $H$, Inoue $Y$, Fujieda T, Kobayashi H. Dietary L-lysine supplementation reduces de novo lipogenesis via AMPK activation and malonyl-CoA suppression. FASEB J 2009; 23:227.6.

26. Friesen KG, Nelssen $J L$, Goodband RD, Tokach MD, Unruh JA, Kropf DH, et al. The effect of dietary lysine on growth, carcass composition, and lipid metabolism in high-lean growth gilts fed from 72 to 136 kilograms. J Anim Sci 1995; 73:3392-3401.

27. Bahadur V, Haldar S, Ghosh TK. Assessment of the Efficacy of L-Lysine Sulfate vis-à-vis L-Lysine Hydrochloride as Sources of Supplemental Lysine in Broiler Chickens. Vet Med Int [en línea] 2010 July 28 [fecha de acceso 22 de enero de 2011]; 2010 (964076), 9 pages. URL disponible en: http:// www.ncbi.nlm.nih.gov/pmc/articles/ PMC2913816/?tool=pmcentrez.

28. Owen $\mathrm{KQ}$, Jit $\mathrm{H}$, Maxwell CV, Nelssen, JL, Goodband RD, Tokach MD, et al. Dietary L-carnitine suppresses mitochondrial branched-chain keto acid dehydrogenase activity and enhances protein accretion and carcass characteristics of swine. J Anim Sci 2001; 79: 3104-3112. 